\title{
LIVRAMENTO CONDICIONAL E FALTA DISCIPLINAR: A incoerência da súmula 441 do STJ em relação ao princípio da progressividade da pena
}

\section{PAROLE AND DISCIPLINARY OFFENSE: The incoherence of the 441 Supreme Court precedent for the principle of progressivity of the sentence}

\author{
Marcos Vinícius Ast de Almeida ${ }^{1}$ \\ Paula Curi Mendes ${ }^{2}$
}

\begin{abstract}
RESUMO: O presente trabalho pretende analisar sistematicamente os benefícios oferecidos aos apenados durante o cumprimento da pena, bem como as causas de interrupção da contagem para esses mesmos benefícios. Assim, observando-se que para o livramento condicional, o maior benefício a ser concedido a um detento, e que permite o seu retorno de forma quase irrestrita em sociedade, não é computada a interrupção temporal da execução de acordo com a prática eventual de novos delitos ou faltas, busca-se oportunizar ao leitor uma abordagem nova do benefício, traçando um parâmetro entre o próprio e o princípio da progressividade da pena. Assim, quer se demonstrar que há uma ilegalidade e discrepância razoáveis entre o livramento, a súmula 441 do STJ e o princípio da progressividade da pena.
\end{abstract}

Palavras-chave: Execução penal. Livramento condicional. Súmula 441.

\begin{abstract}
This paper intends to systematically analyze the benefits offered to inmates during the execution of the sentence, as well as the causes of interruption of the count for these benefits. Thus, noting that for the parole, the biggest benefit to be granted to an inmate, and allowing his return from an almost unrestricted in society, is not computed temporal interruption of execution in accordance with the practice of any new crimes or offenses, seeks to create opportunities for the reader a new approach to benefit, a parameter mapping between itself and the principle of progressivity of the sentence. So, wants to demonstrate that there is a reasonable gap between illegality and deliverance, the sum 441 of the STJ and the principle of progressivity of the sentence.
\end{abstract}

Keywords: Criminal Enforcement. Progression of the sentence. Summary 441.

\section{INTRODUÇÃO}

A doutrina processualista, tanto a cível quanto a penal, sempre enfrentou diversos obstáculos na determinação dos conceitos de jurisdição. Tal não é diferente quando se fala em execução penal, eis que a prática jurisdicional afeta à essa área é caracterizada justamente pelo caráter híbrido, ou seja, não se fala em processo com a caracterização do contencioso, nem no caráter meramente administrativo, uma vez que efetivamente há atuação de um magistrado na impulsão oficial dos procedimentos.

\footnotetext{
${ }^{1}$ Bacharel em Direito

${ }^{2}$ Acadêmica do Curso de Direto da Universidade Federal de Santa Maria/UFSM, $6^{\circ}$ semestre.
} 
Além disso, sabe-se que a execução penal é uma atividade complexa, na qual participam juntos dois poderes: o Executivo e o Judiciário. O primeiro atua nas funções administrativas, como, por exemplo, na criação das casas prisionais; e o segundo desenvolve as funções especificamente jurisdicionais, como a análise de concessão dos benefícios ao apenado. Inclusive, a Lei de Execução Penal (Lei 7.210 de 11 de julho de 1984), faz referência a esses dois poderes: no artigo $2^{\circ}$ menciona a "jurisdição penal dos Juízes ou Tribunais da Justiça ordinária", e no artigo $4^{\circ}$ refere-se ao Estado, ficando evidente a atuação dos poderes Judiciário e Executivo, respectivamente, na execução penal. Juntos, esses dois poderes buscam concretizar os benefícios assegurados ao apenado na LEP.

Atualmente, no entanto, tem-se deturpado severamente os objetivos da prática criminal junto à execução, decorrente da inércia do Poder Executivo a respeito da realidade precária do sistema carcerário brasileiro.

Nesse contexto, o Poder Judiciário tem atuado de maneira supletiva, e assegurado aos apenados benefícios que não são apropriados ao objetivo final da execução, a exemplo do que ocorre com o livramento condicional e a data base.

Sabe-se que a pena deve ser cumprida em caráter progressivo, de acordo com o artigo 112 da Lei de Execução Penal. É corolário lógico desse princípio que devem ser previstas algumas causas interruptivas do cumprimento da pena, iniciando-se novamente a contagem do prazo legal para o deferimento de novos benefícios.

A jurisprudência, consolidada pela súmula 441 do STJ, tem aplicado entendimento divergente ao princípio da progressividade em relação ao livramento, de modo que, para tal benefício, não se interrompe a contagem do requisito legal objetivo ainda que o apenado tenha dado azo à interrupção do prazo da execução quanto a outros benefícios, como ocorre com a progressão de regime, saídas temporárias, etc.

Nesse contexto, portanto, é possível perceber que há certa incompatibilidade na aplicação do princípio da progressividade da pena em comunhão com os benefícios da execução penal. Para a progressão de regime, por exemplo, a prática de falta grave interrompe a contagem do prazo legal para obtenção do respectivo benefício.

Isso, obviamente, em atenção ao princípio da progressividade, o qual, logicamente, não prevê apenas um impulsionamento futuro do processo, mas também sua regressividade, quando ocorrida causa interruptiva. 
Falar-se em progressividade não é apenas dizer que a cada período cumprido o apenado tem direito à liberdade de forma homeopática, mas sim que o processo deve seguir uma lógica indispensável aos objetivos da execução.

No presente trabalho, portanto, propõe-se uma reflexão sobre a efetiva aplicação do princípio da progressividade da pena, procurando-se demonstrar de forma crítica que a jurisprudência atual, cuja matéria já foi inclusive sumulada, tem deturpado a aplicação do livramento condicional e ofendendo, por consequência, o princípio da progressividade da pena, o qual merece entendimento não tão superficial como o que ora lhe é atribuído.

\section{OS OBJETIVOS DA LEI DE EXECUÇÃO PENAL}

A finalidade da execução penal é, conforme o artigo $1^{\circ}$ da LEP, "efetivar as disposições de sentença ou decisão criminal e proporcionar condições para a harmônica integração social do condenado e do internado".

Já a Lei de Execução Penal tem como objetivo primordial a ressocialização do apenado, de modo a reeducá-lo para que não volte a delinquir e torne-se novamente membro da sociedade. Para cumprir tal objetivo, a LEP prevê que a pena seja cumprida de maneira adequada, assegurando ao preso e ao internado assistências de diversas espécies, bem como que o cumprimento da pena se dê em estabelecimento compatível com a sua finalidade. Ainda, assegura ao apenado diversos direitos, recompensas e benefícios. Estes últimos são imprescindíveis no curso da execução de uma condenação, uma vez que propiciam que o apenado retorne gradativamente ao convívio em sociedade (RANGEL, 2006, p. 465).

\section{OS BENEFÍCIOS ASSEGURADOS PELA LEP}

A Lei 7.210 de 1984 assegura ao condenado benefícios a serem deferidos no curso da execução penal mediante implementação de determinados requisitos.

A remição, prevista nos artigos 126 a 130 da Lei de Execução Penal, é um desses benefícios. A remição é o direito que o condenado em regime fechado ou semiaberto possui de, a cada 03 dias de trabalho, ter descontado 01 dia da pena. Ademais, graças à alteração da Lei 12.433 de 29/06/2011, agora é possível remir também o período de 
estudo, na razão de 12 horas de estudo para 01 dia de pena descontado. Tal entendimento já era aplicado pelas Varas de Execução Criminal em razão da súmula 341 do STJ. Com a inovação legislativa, a remição por tempo de estudo passou a ser expressamente prevista na LEP.

Prevista no artigo 42 do Código Penal Brasileiro, a detração é outro benefício assegurado pela LEP. Trata-se do direito que o condenado possui de ter descontado do total da pena privativa de liberdade, ou da medida de segurança, o período que permaneceu em prisão provisória, no Brasil ou no estrangeiro, em prisão administrativa e em internação em qualquer dos estabelecimentos referidos no artigo 41 do Código Penal.

Outra previsão da Lei 7.210 é o serviço externo (artigos 36 e 37). Para o preso que cumpre pena no regime fechado, o trabalho externo só poderá ser exercido em serviços ou obras públicas, inclusive nas realizadas por empresas privadas, desde que sejam tomadas as devidas precauções para evitar fugas. O preso que cumpre pena em regime semiaberto ou aberto pode exercer o serviço em empresas privadas sem fiscalização direta. Contudo, poderá ser determinado pelo juiz ou pelo promotor da Vara de Execuções Criminais que o serviço desempenhado pelo apenado seja fiscalizado em determinados períodos. Para que o apenado usufrua de serviço externo deverá implementar dois requisitos: o subjetivo e o objetivo. $O$ primeiro refere-se ao comportamento carcerário do apenado, e o segundo diz respeito ao lapso temporal que o apenado deve cumprir antes de ter direito ao serviço externo.

Da mesma forma que o trabalho externo, as saídas temporárias também são concedidas mediante implementação dos requisitos subjetivo e objetivo. Esse benefício vem assegurado na LEP nos artigos 122 a 125 e corresponde ao direito que o apenado tem de sair temporariamente e sem fiscalização direta do estabelecimento em que cumpre pena.

A progressão de regime, por sua vez, é um dos mais importantes benefícios assegurados pela Lei de Execução Penal. Prevista em seu artigo 112, é a passagem de um regime de cumprimento de pena mais rigoroso para outro mais brando. Para isso, o apenado deve implementar os mesmos requisitos necessários à concessão do serviço externo. Conveniente referir que a LEP também prevê, em seu artigo 118, que ocorra a regressão de regime, ou seja, que o condenado volte a um regime mais rigoroso em razão de ter descumprido alguma condição prevista para o regime em que estava ou de 
ter cometido alguma falta disciplinar. A regressão de regime pode dar-se por "salto", ou seja, poderá um apenado regredir do regime aberto diretamente para o fechado, em que pese o mesmo não ser possível quando na progressão (MIRABETE, 2008, p. 553).

Por fim, o maior benefício assegurado pela Lei 7.210 é o livramento condicional. Previsto nos artigos 131 a 146 da LEP, é uma espécie de "antecipação" da liberdade do condenado, que retorna completamente ao convívio em sociedade mediante o cumprimento de condições estabelecidas pelo juiz da Vara de Execuções Criminais. Para sua concessão, o apenado também deve implementar os requisitos subjetivo e objetivo. Da mesma forma que na progressão de regime, o requisito subjetivo diz respeito ao comportamento do apenado, que pode ser analisado através de um atestado de conduta carcerária fornecido pela administração prisional, através de exame psicossocial além da análise do histórico do cumprimento da pena. Convém ressaltar que, por se tratar de um benefício maior, a análise do comportamento do apenado deve ser mais rigorosa. $\mathrm{O}$ segundo diz respeito à quantidade de pena que o condenado deverá cumprir antes de fazer jus ao benefício. Trata-se de cumprimento de um terço da pena quando o delito não for hediondo e o apenado for primário, e metade da pena se o apenado for reincidente. Sendo o delito hediondo, o apenado, reincidente ou não, deverá cumprir dois terços de sua pena antes de obter o livramento. Esses requisitos estão previstos no artigo 83 do Código Penal Brasileiro (NUCCI, 2011, p. 756).

\section{CAUSAS INTERRUPTIVAS DO TEMPO DE EXECUÇÃO}

A execução penal, em tese, deve ser cumprida ininterruptamente, ou seja, sem intercorrências que possam acarretar na alteração da "data base", ou seja, em um novo marco temporal para cálculo de benefícios.

Em que pese a falta de previsão legal, a alteração da data base há muito vem sendo aplicada pelos magistrados de Varas de Execução Criminal como forma de sanção ao apenado que, por exemplo, comete uma falta grave. A principal fundamentação ao alterar-se a data base é o fato de que, punir o apenado com a regressão de regime (sanção prevista no artigo 118, inciso I, da LEP) sem novo marco interruptivo é um contra-senso, já que no dia seguinte ao recolhimento do condenado em regime mais gravoso ele já teria, em tese, cumprido o requisito objetivo para progressão. Isso, por que se nada foi alterado, permanece a situação fática quanto ao requisito objetivo, que, 
evidentemente, já foi implementado, uma vez que o apenado estava em regime mais brando.

Para evitar esta situação, a alteração da data base mostra-se a solução mais adequada (NUCCI, 2011, p. 785).

Nesse sentido, a principal causa interruptiva do tempo de execução é a prática de fato definido como falta grave. De acordo como artigo 50 da Lei de Execução Penal, comete falta grave o condenado à pena privativa de liberdade, ou o preso provisório, que: incitar ou participar de movimento para subverter a ordem ou a disciplina; fugir; possuir, indevidamente, instrumento capaz de ofender a integridade física de outrem; provocar acidente de trabalho; descumprir, no regime aberto, as condições impostas; inobservar os deveres previstos nos incisos II e V, do artigo 39, da LEP; tiver em sua posse, utilizar ou fornecer aparelho telefônico, de rádio ou similar, que permita a comunicação com outros presos ou com o ambiente externo. Outrossim, conforme o artigo 52 da mesma Lei, a prática de fato previsto como crime doloso também constitui falta grave.

$\mathrm{O}$ apenado que comete qualquer um desses fatos, dessa forma, deve ter a data base alterada, a fim de que, a partir dela, inicie o cumprimento de novo lapso temporal para obter direito a novos benefícios externos.

\section{O PRINCÍPIO DA PROGRESSIVIDADE DA PENA}

O princípio da progressividade da pena é inferido da compreensão do artigo 112 da Lei 7.210/84, o qual estabelece que "a pena privativa de liberdade será executada em forma progressiva com a transferência para regime menos rigoroso (...)".

A forma progressiva diz respeito ao fato de que os condenados à pena privativa de liberdade devem cumprir a pena passando pela "seqüência" dos regimes, ou seja, se iniciado o cumprimento em regime fechado, o próximo deverá ser o semiaberto e só então o aberto. Assim, a execução ocorre de forma gradual e adequada, possibilitando a melhor maneira de reinserir o apenado na sociedade, já que o mesmo retorna aos poucos para o convívio social (LOPES JR., 2010, p. 357).

Por outro lado, o princípio da progressividade da pena também diz respeito ao livramento condicional. O livramento é o maior benefício concedido ao apenado, pois esse tem sua liberdade antecipada, ficando apenas com o dever de atender a algumas 
condições estabelecidas pelo magistrado que deferiu o benefício. Por esse motivo, o livramento condicional deve ser reservado somente aos apenados que demonstrem real lisura no cumprimento de sua pena, e que demonstrem estar aptos a retornar ao convívio em sociedade.

Para isso, o apenado não deve ter o livramento concedido juntamente quando progredir ao regime semiaberto, pois, se for assim, ele sairá do regime fechado diretamente para o livramento. Tal situação dificulta a readaptação do apenado ao convívio social, já que isso não se operou de maneira gradual, com a passagem pelos regimes semiaberto e aberto.

Por esses motivos, mostra-se mais adequado que o apenado somente obtenha o livramento quando já estiver no regime aberto, ou, no mínimo, no semiaberto, a fim de que possa readaptar-se à sociedade da melhor maneira possível. O fato é que, ao adentrar nesse assunto, fala-se em uma questão muito polêmica na temática afeta à execução penal, qual seja a alteração da data base para os benefícios externos, o que não ocorre com o livramento condicional, a despeito da súmula 441 do STJ, como se verá a seguir.

\section{A SÚMULA 441 DO STJ E SUA REPERCUSSÃO NO LIVRAMENTO CONDICIONAL}

Conforme o texto da súmula 441 do Superior Tribunal de Justiça, para o livramento condicional não devem ser computadas as alterações na data base dos benefícios externos conferidos ao apenado durante o período de execução.

Conforme já referido em oportunidade anterior, o livramento condicional é o maior dos benefícios conferidos ao apenado. O que se propõe no presente trabalho é, em suma, demonstrar ser incongruente a previsão legal da súmula, pois atenta contra o próprio princípio da progressividade da pena. Veja-se.

O apenado que inicia o cumprimento da pena em regime fechado, após o implemento do lapso necessário, dependendo do delito que cometeu (se hediondo ou comum), bem como após a satisfação do requisito subjetivo, obviamente terá direito à progressão de regime. Passará, assim, ao regime semiaberto e após, sucessivamente, caso cumpridas novamente as determinações legais, ao regime aberto. 
A não satisfação dos requisitos previstos em lei, certamente, é resultado de que o processo de execução da pena, de certa forma, não surtiu o efeito desejado ao apenado em relação ao crime que cometeu. Tem-se uma idéia errônea de que a pena tem o condão de ressocializar os detentos. No entanto, o ideal seria considerá-la como um meio de conscientizar os presos a respeito da gravidade dos seus delitos e, por meio desse processo de conscientização, agir paralelamente na reestruturação social do apenado.

Isso significa que não há como ressocializar alguém que não estava socializado. E por socializado, entenda-se aquele que age conforme os parâmetros estabelecidos em sociedade. Da mesma forma, sabe-se que a maioria da população carcerária é de pessoas pobres e que, antes mesmo de estarem encarceradas, já se encontravam inseridas em um processo de marginalização e distanciamento do convívio direto com a sociedade (MACHADO, 2009, p. 632).

Alguém que nasce em uma comunidade extremamente pobre e não tem oportunidade de estudo, seja por preconceito ou por ignorância dos pais, e que convive durante sua juventude com pessoas semelhantes e que também não possuem instrução suficiente para traçar certos objetivos, dificilmente terá uma realidade ou futuro comparável a daquele que nasce em uma família de classe média ou alta (ALTAVILLA, 1982, p. 321).

Assim, percebe-se que o ideal seria não ressocializar, mas oportunizar um processo de oferecimento de possibilidades pessoais e, com o auxilio dos profissionais competentes, como psicólogos e assistentes sociais, incutir nos detentos a formação de determinados conceitos e sensos de criticismo diante da realidade.

Quando, durante a execução, o apenado comete faltas ou dá azo à interrupção de sua contagem temporal, significa que não está apto para receber os benefícios que conferem à execução um certo caráter progressivo. Este representa uma forma sistemática de oferecer ao executado um retorno gradual ao convívio em sociedade. Do contrário, deve permanecer segregado no regime em que atualmente cumpre pena, até que satisfaça os requisitos necessários (ESPÍNOLA FILHO, 2006, p. 744).

Imagine-se a situação de um apenado que, cada vez que recebia progressão de regime, cometia um novo delito ou falta, seja ela fuga, posse de celular no interior da casa prisional ou de drogas. Para cada falta ou delito, que também é uma infração 
disciplinar, seria estabelecido um novo parâmetro para a contagem dos lapsos dos benefícios externos, como saídas temporárias, progressão, trabalho externo, etc.

Isso, obviamente, pois o sentenciado não ostenta os critérios de legitimação do regime mais brando da pena. Assim, deve permanecer cumprindo a pena em regime gravoso, até que importe no cumprimento do novo lapso temporal.

Para o livramento condicional, no entanto, essa interrupção, segundo o teor da súmula 441 do STJ, não deve ser levada em consideração. Assim, conta-se o prazo do livramento a partir do início do cumprimento da pena, ainda que durante ela o apenado tenha cometido inúmeras faltas ou novos crimes.

Observa-se, portanto, que o atual entendimento acerca do livramento é contrário ao próprio princípio da progressividade da pena. Afinal, há um esvaziamento do processo de oportunização do apenado estabelecer determinados parâmetros de convívio em sociedade.

Desse modo, aquele apenado que cometeu as faltas de acordo com o caso fictício anteriormente explicitado, mesmo se cumprindo pena em regime fechado, passará direto a usufruir o livramento condicional, ainda que tenha demonstrado por diversas vezes e no curso da execução, ainda não estar totalmente preparado para retornar ao mundo externo de forma plena.

Até mesmo porque, conforme itens anteriores, o livramento estabelece o retorno quase total do apenado em sociedade. Ele apenas deverá comparecer sucessivamente em juízo, de acordo com o estabelecido judicialmente, bem como comunicar eventuais ausências da Comarca onde cumpre pena. Quanto ao mais, permanecerá circulando livremente, sem restrição direta de sua liberdade de ir e vir, bem como do seu contato direto em sociedade.

\section{CONCLUSÃO}

Disso tudo se extrai que a atual aplicabilidade dos institutos da execução penal, em especial do livramento condicional, merece uma atenção maior pelos julgadores e legisladores, a fim de que seja repaginada a ótica atualmente atribuída ao princípio da execução da pena.

Deve-se buscar uma nova forma de estruturação da execução penal, possibilitando um processo de cumprimento da pena sem que ocorram as discrepâncias que vem sendo 
aplicadas atualmente, como permitir que um apenado que recém cometeu novo delito tenha o direito de receber o livramento condicional e passar a cumprir o restante da pena em quase total liberdade. Veja-se que não há progressividade nesse caso. Há, sim, um pulo de um regime mais grave para o maior dos benefícios da execução. Caso este que somente é permitido em situações de erro judiciário.

Assim, é importante levar em consideração que o princípio da progressividade na execução da pena deve ter como condão o preenchimento gradual das condições de o apenado retornar ao convívio social, esvaziando, assim, o seu periculum libertatis, bem como quando não há mais interesse social e do Estado na sua prisão.

\section{REFERÊNCIAS}

AltaVIlla, Enrico. Psicologia Judiciária: Personagens do Processo Penal. $3^{\text {a }}$ Ed. Coimbra: Armênio Amado, 1982.

ESPÍNOLA FILHO, Eduardo. Código de Processo Penal Brasileiro Anotado. $5^{\text {a }}$ Ed. Rio de Janeiro: Rio, 2006.

LOPES JR., Aury. Direito Processual Penal e sua Conformidade Constitucional.

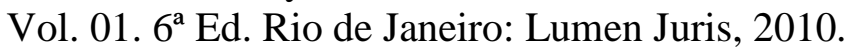

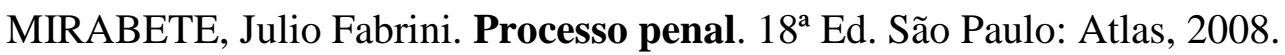

MACHADO, Antonio Alberto. Curso de Processo Penal. $2^{a}$ Ed. São Paulo: Atlas, 2009.

NUCCI, Guilherme de Souza. Manual de Processo Penal e Execução Penal. $7^{\text {a }}$ Ed. São Paulo: Editora Revista dos Tribunais, 2011.

RANGEL, Paulo. Direito Processual Penal. 11 ${ }^{\text {a }}$ Ed. Rio de Janeiro: Lumen Júris, 2006. 